\title{
From Really Being to Being Represented
}

A Synoptic Overview of Peirce's Pragmaticist Doctrine of the Truth of Propositions

Jeoffrey Gaspard

\section{(2) OpenEdition}

1 Journals

\section{Electronic version}

URL: http://journals.openedition.org/ejpap/1908

DOI: 10.4000/ejpap.1908

ISSN: 2036-4091

\section{Publisher}

Associazione Pragma

\section{Electronic reference}

Jeoffrey Gaspard, «From Really Being to Being Represented », European Journal of Pragmatism and American Philosophy [Online], XII-1 | 2020, Online since 16 June 2020, connection on 26 June 2020. URL : http://journals.openedition.org/ejpap/1908; DOI : https://doi.org/10.4000/ejpap.1908

This text was automatically generated on 26 June 2020 .

\section{(c) $(1) \odot$}

Author retains copyright and grants the European Journal of Pragmatism and American Philosophy right of first publication with the work simultaneously licensed under a Creative Commons AttributionNonCommercial-NoDerivatives 4.0 International License. 


\title{
From Really Being to Being Represented
}

\author{
A Synoptic Overview of Peirce's Pragmaticist Doctrine of the Truth of \\ Propositions
}

Jeoffrey Gaspard

\section{Introduction}

1 This paper is addressed to scholars (among which I include myself) unfamiliar with Peirce's thought as a whole and aims at reaffirming that his entire philosophy shall be conceived as an integrated (yet fragmentary) system, a characteristic which has often been shrugged aside in unsuspecting disciplines (e.g. language, media, or literary studies). For instance, as far as semiotics is concerned, I gradually came to realize, with Short (2007: ix), that "Peirce's theory of signs [has indeed been] taken up by an interdisciplinary army of 'semioticians' whose views and aims are antithetical to Peirce's own, and meanwhile [...] has been shunned by those philosophers who are working in Peirce's own spirit on the very problems to which his semeiotic was addressed." This often led many works, among them introductory monographs about signs in general, to focus on specific parts unfortunately severed from the whole, leaving those amputated fragments at best difficult to understand or at worst desperately meaningless.

2 Within this perspective, I will strive to provide a "synoptic" overview of Peirce's “ pragmaticist" doctrine of the truth of propositions. Two reasons have led to this choice of topic. The first is that Peirce's perspective on propositions, I believe, is a good way of illustrating the fundamental interrelations between his metaphysical, phenomenological, and semeiological views. The second reason is I think this topic constitutes a good entry point to reflect upon Peirce's pragmaticist approach as a whole. In order to do so, I will mostly rely on Peirce's own writings, as I came to believe that no one was as incisive as Peirce himself, provided each of his thoughts are repositioned on the chronological line of his intellectual development. Indeed, as Max 
Fisch (1986) and others have shown (see, in particular, Murphey 1961; Freadman 2004; Short 2007; Bergman 2009b; and Bellucci 2018), Peirce's views did greatly evolve over time, but that envisioned "philosophical edifice" was already there in the making, as a guiding principle governing all his work.

3 In the first place, I will thus briefly present Peirce's fundamental "conceptions," which are central to his philosophical system, irrigating all of its branches. In the second place, I will survey Peirce's "Kantian step" of transferring those conceptions of logic to metaphysics, yielding three kinds of "real elements" whose respective characters are quite distinct. In the third place, I will describe how those three kinds of realities must necessarily be implied in a pragmaticist approach of true propositions, understood as final beliefs to which inquiries carried sufficiently far are ultimately destined to lead.

\section{Toward the Kantian Step}

4 In the famous Guess at the Riddle essay, written in the winter of 1887-1888, Peirce declared that his ambition was "to make a philosophy like that of Aristotle, that is to say, to outline a theory so comprehensive that, for a long time to come, the entire work of human reason, in philosophy of every school and kind, in mathematics, in psychology, in physical science, in history, in sociology, and in whatever other department there may be, shall appear as the filling up of its details" (W6: 168 [1887-88]). More specifically, he insisted that "to erect a philosophical edifice that shall outlast the vicissitudes of time, my care must be, not so much to set each brick with nicest accuracy, as to lay the foundations deep and massive," and argued in consequence that the first step toward the foundational building of a systematic philosophy was to find "simple concepts applicable to every subject" (W6: 169 [1887-88]).

5 In the New List of Categories, published twenty years earlier, Peirce had actually presented such a list of conceptions, or categories, understood as "the fundamental ones of at least one universal science, that of logic" (W2: 56 [1868]), and which he formally deduced from a formal analysis of the structure of propositions. ${ }^{1}$ However, Peirce repeatedly conceded that his conceptions, which "meet us not once but at every turn" (W6: 182 [1887-88]), were rather "vague ideas." For instance, in his Architecture of Theories, published in an 1891 issue of the Monist, he admitted that "they are conceptions so very broad and consequently indefinite that they are hard to seize and may be easily overlooked" (W8: 109 [1891]). In the same vein, in his second 1898 Cambridge lecture, he argued that it was "to be remembered that they are excessively general ideas, so very uncommonly general that it is far from easy to get any but a vague apprehension of their meaning" (CP 4.3. [1898]); and in a 1903 letter to William James, he confessed also that "to make them as distinct as it is in their nature to be is, however, no small task. I do not suppose they are so in my own mind; and evidently, it is not in their nature to be sharp as ordinary concepts" (CP 8.264 [1903]).

More precisely, Peirce conceived these fundamental conceptions to be "no more than the ideas of First, Second, and Third, - ideas so broad that they may be looked upon rather as moods or tones of thought, than as definite notions" (W6: 169 [1887-88]). What is more, he emphasized that "if there are any three-fold distinctions that are more than verbal, their real nature will clearly be elucidated by an understanding of the meanings of the numbers one, two, three, provided that there are any such 
meanings" (ibid.: 170). Now, in the most abstract of form, according to Peirce, third is the conception of that which is related to two other things, in such wise that it brings them into relation (because we cannot conceive anything third without necessarily conceiving something first and something second: third implies first and second); second is the conception of that which is related to something else, but regardless of any third thing bringing them into relation (because we may not conceive something second without necessarily conceiving something first, but we may conceive something second without necessarily conceiving anything third: second implies first but does not imply third); and first is the conception of that which is unrelated to nothing else (because we may conceive something first without necessarily conceiving something second nor something third: first does not imply second nor third).

7 Those three irreducible categories being vague and hardly definable, I propose to take "the Kantian step of transferring the conceptions of logic to metaphysics" (R 439: 1 [1898]) and examine their application to the "real world." Peirce argued indeed that the three categories of logic "should be the three elementary conceptions of metaphysics" on the ground that "Nature only appears intelligible so far as it appears rational, that is, so far as its processes are seen to be like processes of thought" (CP 3.422 [1892]). Such a metaphysical point of view, I believe, shall help us understand even more clearly "what are the kinds of objects that are first, second, and third, not as being so counted, but in their own true characters" (W6: 170 [1887-88]). For three fundamental categories of characters, or "modes of being," may indeed be deduced from what was stated above: firstness, secondness, and thirdness. Firstness is the mode of being of that which is first, or that which is such as it is, in being unrelated to nothing else; secondness is the mode of being of that which is second, or that which is such as it is, in being related to something else but regardless of anything else; and thirdness is the mode of being of that which is third, or that which is such as it is, in bringing two other things into relation. Let us now see how the categories enter into real elements.

\section{Possible Qualities, Actual Existents, and General Laws}

One of Peirce's original contributions to philosophy consists in a passionate defense of his own version of scholastic realism (see, for instance, Boler 1963; Engel-Tiercelin 1992; and Lane 2018), whereby he contended that the real, understood as that which is such as it is independently of its being so represented, ${ }^{2}$ was not to be reduced to mere existence.

This, however, contradicted a seminal tenet of nominalism, "this stupid and utterly anti-scientific doctrine" ( $\mathrm{R}$ 778: 12 [ca. 1909]). According to Peirce indeed, the nominalists "hold that existence, - the reaction of things against the other things of the universe, - is the only mode of real being while the Scotists, like Aristotle and Plato, held that besides the existent realities there are higher kinds of reality; laws that regulate the universe though they cannot be said to exist, as well as potentialities or germs of being not yet developed into actual existence"s (R 778: 12 [ca. 1909]). As a matter of fact, an important evolution of Peirce's thought, spanning almost thirty years, consisted in this gradual recognition of those three "independent or distinct elements of the triune Reality" (EP2: 345 [1904]), which any serious philosophical system shall recognize as its ingredients: possible qualities, actual facts, and general laws. 
This, for instance, led him to suggest a division of the most important metaphysical systems having emerged in the history of philosophy "based upon the consideration of what ones of the three categories each of the different metaphysical systems has fully admitted as real constituents of nature" (EP2: 179 [1903]).

\subsection{Possible Qualities are Real}

10 The first category comprises all qualities, which may be conceived as firsts, being such as they are, regardless of anything else. Indeed, "a quality is whatever it is in itself. It has such mode of being as it has independently of any other quality, of existing in any subject, and of being represented" (R 8: 1 [ca. 1904?]. It follows that any given quality, because it is such as it is in itself and would so remain even if it never were never embodied in anything, is in some sense eternal: "a pure quality, in its mode of being as a pure quality, does not cease to be because it is not embodied in anything" (R 7: 12 [ca. 1903?]). Said Peirce, in the 1903 Syllabus of Certain Topics of Logic: "look at anything red. That redness is positively what it is. Contrast may heighten our consciousness of it; but the redness is not relative to anything; it is absolute, or positive. If one imagines or remembers red, his imagination will be either vivid or dim; but that will not, in the least, affect the quality of the redness, which may be brilliant or dull, in either case. The vividness is the degree of our consciousness of it, its reaction on us. The quality in itself has no vividness or dimness" (EP2: 268 [1903]). Accordingly, "it seems undeniable that there really are such possibilities, and that, though they are not existences, they are not nothing" (EP2: 269 [1903]). ${ }^{4}$

11 From a phenomenological point of view, we are conscious of qualities whenever we happen to feel anything: "Imagine me to make and in a slumberous condition to have a vague, unobjectified, still unsubjectified, sense of redness, or of salt taste, or of an ache, or of grief or joy, or of a prolonged musical note. That would be, as nearly as possible, a purely monadic state of feeling. Now in order to convert that psychological or logical conception into a metaphysical one, we must think of a metaphysical monad as a pure nature, or quality, in itself without parts or features, and without embodiment" (CP 1.303 [1894]). As a matter of fact, artists are particularly attuned to that state of mind which consists in contemplating "what stares one in the face, just as it presents itself" (EP2: 147 [1903]). For instance, "when the ground is covered by snow on which the sun shines brightly except where shadows fall, if you ask any ordinary man what its color appears to be, he will tell you white, pure white, whiter in the sunlight, a little greyish in the shadow. But that is not what is before his eyes that he is describing; it is his theory of what ought to be seen. The artist [however] will tell him that the shadows are not grey but a dull blue and that the snow in the sunshine is of a rich yellow." In any case, thus, "whenever we are awake, something is present to the mind, and what is present, without reference to any compulsion or reason, is feeling" (EP2: 4 [1894]). Our feelings, therefore, testify to the reality of possible qualities.

\subsection{Actual Existents are Real}

The second category of real elements comprises all existents, which may be conceived as seconds, being such as they are, related to something else, but regardless of anything else. Using the word "in its strict philosophical sense" (CP. 6.495 [1906]), Peirce thus argued that "the existent is that which reacts against other things" (CP 8.191 [1903]) in 
pairs, and that "what is meant by Existence consists in each existent reacting [...] with all the other existents of the same universe" (R 939: 35 [1905]) - a mode of being that a mere quality is incapable of enjoying. For instance, "to say there is a phantom table [...] incapable of affecting any senses or of producing any physical effects whatever, is to speak of an imaginary table. A thing without oppositions ipso facto does not exist. [...] Not only is this opposition essential to an individual thing or subject, but also to an individual fact. Its truth, or existence, is the sum of its effects" (CP 1.457 [ca. 1896]). Remember that this mode of being was the only one conceived to be real by the nominalists: for "the heart of the dispute lies in this. The modern philosophers - one and all, unless Schelling be an exception - recognize but one mode of being, the being of an individual thing or fact, the being which consists in the object's crowding out a place for itself in the universe, so to speak, and reacting by brute force of fact, against all other things" (CP 1.21 [1903]).

Hence, the mode of being of an existent thing does not consist in a mere possibility, like that of pure qualities, but in its brute actuality: its being, therefore, "does not consist in any qualities, but in its effects - in its actually acting and being acted on, so long as this action and suffering endures. Those who experience its effects perceive and know it in that action; and just that constitutes its very being. It is not in perceiving its qualities that they know it, but in hefting its insistency then and there, which Duns called its haecceitas"5 (CP 6.318 [ca. 1909]). However, "if all its qualities were to be taken away, and it were to be left quality-less matter, it not only would not exist, but it would not have any positive definite possibility - such as an unembodied quality has. It would be nothing at all" (CP 1.527 [1903]). Existents, therefore, may not be prescinded ${ }^{6}$ from the qualities which they embody, although those embodied qualities may be prescinded from them.

More specifically, an existent is to be conceived as the subject of an actual fact, which may be of two possible kinds: (1) "monadic" facts, which consist in its embodying some possible quality and (2) "dyadic" facts, which consist in its standing in a relation with some other existent. Dyadic facts may themselves be divided into two possible kinds: first, those which consist, for their subject, in its being qualitatively related to another existent by virtue of a quality which they would both happen to possess, and those which consist, for their subject, in its being dynamically related to another existent by virtue of acting on, or of being acted upon by, the other. In that latter case, the reaction necessarily determines a quality which would otherwise not be there in one or both of the related existents: any dynamic relation necessarily produces an effect.

From a phenomenological point of view, we are conscious of actual existents whenever we happen to react with anything forcing itself upon ourselves: "this sense of acting and of being acted upon, which is our sense of the reality of [existent] things, - both of outward and of ourselves, - may be called the sense of Reaction. It does not reside in any one Feeling; it comes upon the breaking of one feeling by another feeling" (EP2: 4 [1894]). In other words, a reaction is "that which we experience when our will meets with resistance, or when something obtrudes itself upon sense" (R 439: 6 [1898]). That which brutely reacts against us, therefore, is an insistent other, a non-ego which resists to its being modified, and this very reluctance is what distinguishes existents from mere fancies of the mind which "yield at once to a direct effort of the will" (EP2: 65 [1901]). This definition corresponds to what we generally call experience, as being that which brutely forces itself upon us in the course of life. Note also that actual existents 
conceived as being perceived are called percepts and constitute, as such, the bedrocks of perceptual facts. The latter, as I mentioned, may either be "monadic" or "dyadic," for something may immediately, or directly, be perceived as embodying a quality or as reacting against another thing. Our senses of reaction, therefore, testify to the reality of actual existents.

\subsection{General Laws are Real} they are in bringing qualities and existents into relation. Peirce remarked indeed that "nobody can doubt that we know laws upon which we can base predictions to which actual events still in the womb of the future will conform to a marked extent, if not perfectly. To deny reality to such laws is to quibble about words" (EP2: 269 [1903]). For instance, it is a given truism that "with overwhelming uniformity, in our past experience, direct and indirect, stones left free to fall have fallen" (EP2: 183 [1903]). In order to make sense of this, however, "two hypotheses only are open to us. Either: first, the uniformity with which those stones have fallen has been due to mere chance and affords no ground whatever, not the slightest, for any expectation that the next stone that shall be let go will fall; or, second, the uniformity with which stones have fallen has been due to some active general principle, in which case it would be a strange coincidence that it should cease to act at the moment my prediction was based upon it" (ibid.). Of course, as the realist he was, Peirce opted for the second hypothesis.

17 Accordingly, the 1903 Syllabus stated that if "there be a regularity that never will be and never would be broken, that has a mode of being consisting in this destiny or determination of the nature of things that the endless future shall conform to it, that is what we call a law. Whether any such law be discoverable or not, it is certain we have the idea of such a thing, and should there be such a law, it would evidently have a reality, consisting in the fact that predictions based on it would be borne out by actual events" (EP2: 269 [1903]). More specifically, a general law, the instantiation of which applies to actual existents whenever corresponding conditional events are actually fulfilled, is therefore expressible in a general conditional proposition of the form "if..., then...," 9 and is to be conceived as expressing a consequence, or general relation subsisting between an antecedent general fact as cause and its consequent general fact as effect. The mode of being of laws, therefore, consists in their general power of government, applicable to an infinite collection of occasions even if those occasions never actually get to occur.

From a phenomenological point of view, we are conscious of laws whenever we happen to reason in thoughts, that is, go through an intellectual process "by which a phenomenon is found to be governed by a rule, or has a general knowable way of behaving" (EP2: 5 [1894]). Hence, the law according to which dropped stones would fall, for instance, is not immediately apprehended in consciousness, as feelings or actual existents may be apprehended: a law is indeed necessarily thought, that is, represented. However, the fact that any good law is a represented law, or is dependent upon representation, does not in the least imply that it cannot be real. In a famous passage of his fourth 1903 Harvard Lecture, which I reproduce here in full because of its clarity, Peirce thus argued that "the general proposition that all solid bodies fall in the absence of any upward forces or pressure, this formula, I say, is of the nature of a 
representation. Our nominalistic friends would be the last to dispute that. They will go so far as to say that it is a mere representation, - the word mere meaning that to be represented and really to be are two very different things; and that this formula has no being except as being represented. It certainly is of the nature of a representation. That is undeniable, I grant. And it is equally undeniable that that which is of the nature of a representation is not ipso facto real. In that respect there is a great contrast between an object of reaction [i.e. an actual existent] and an object of representation. Whatever reacts IS ipso facto real. But an object of representation is not ipso facto real. If I were to predict that on my letting go of the stone it would fly up in the air, that would be mere fiction; and the proof that it was so would be obtained by simply trying the experiment. That is clear. On the other hand, and by the same token, the fact that I know that this stone will fall to the floor when I let it go [...] is the proof that the formula, or uniformity, as furnishing a safe basis for prediction, is, or if you like it better, corresponds to, a reality" (EP2: 181 [1903]).

In other words, provided it is truly represented, a given law, in so far as it would bring about the predictions which it conditionally implies, cannot be conceived as a mere formula, or representation: it may be just as real. ${ }^{10}$ It follows that a general law "that consists in the fact that the subject of it would, under certain conditions, behave in a certain way, is Real, provided this be true whether actual persons think so or not; and it must be admitted to be a Real Habit, even if those conditions never actually do get fulfilled" (EP2: 457 [1909]).

Note that, as a matter of fact, it is precisely because we know that some determinate effect would ensue, provided conditional events are fulfilled, that we are capable of purposive action. For instance, our knowing that a bullet shot at someone would necessarily kill that person is a necessary prerequisite for our really killing someone on purpose, provided we actually shoot a bullet. Conversely, we also know that no one could be killed in such a manner if no bullet is actually shot, i.e. if the law's conditional events are not actually fulfilled for it to instantiate itself. Our reasonings, therefore, and the rightful predictions which they allowed us to foresee, testify to the reality of general laws.

\subsection{A Triune Reality of Firsts, Seconds, and Thirds}

Peirce's categorial scheme thus provided him with a logical apparatus for deducing three fundamental kinds of real elements: possible qualities, actual existents, and general laws. Qualities, as firsts, may be prescinded from existents, which existents (and their facts), as seconds, may be prescinded from laws, as thirds. Laws, on their side, are unprescindible from either two, just as existents are unprescindible from qualities. In the draft of an unpublished paper, On the Logic of Quantity, probably written around 1895, Peirce summarized his metaphysical doctrine in the following terms: "We remark in the world three categories of elements. The first comprises the qualities, such as red, butter, tedious, hard, heart-rending, agreeable, and doubtless manifold varieties which are utterly unknown to us. They are potentialities and general in their nature, but there is no reason why any of them should be as it is. The second category comprises actual occurrences. They are individual and brutely insistent. The third category comprises laws. No fact nor collection of facts can constitute a law which goes beyond 
any completed facts to determine how facts that may be shall be characterized. In these, the ideal world of qualities and the world of facts overlap" (R 13: 4 [ca. 1895]).

In metaphysics, therefore, firstness, secondness, and thirdness correspond to the modes of being of that which is merely possible (i.e. qualities), that which is actual (i.e. existents), and that which is general (i.e. laws), respectively. This is the reason why Peirce argued that "there must be three categories of things: first, those which are such as they are regardless of anything else, like the living consciousness of a given kind of feeling, say of red ; secondly, those which are such as they are by virtue of their relation to other things, regardless of any third things, which is the case with the existence of all bodies, whose reality consists in their acting on each other, in pairs; thirdly, those which are such as they are by virtue of bringing two others into relation, as signs of all sorts are [e.g. thoughts of laws] such only so far as they bring their significations to bear upon the objects to which they are applied" (EP2: 427 [1907]). As it is now clear, those three categories of "things" are the three categories of real elements constitutive of a "triune Reality," in so far as "the being of the quality lies wholly in itself, the being of the [existent] thing lies in opposition to other [existent] things, the being of the reason [i.e. laws, in so far as they are represented] lies in its bringing qualities and things together" (CP 1.515 [ca. 1896]).

Now, we have seen that each kind of real elements are phenomenologically apprehended through three different states of mind: our feelings are feelings of qualities, our reactions are reactions of existents, and our reasoning in thoughts are thoughts of laws. However, the fact that these elements are necessarily relative to mind does not imply that they may not be real, that is, be such as they are, independently of what any particular mind or minds may think (or represent) them to be. This highlights an important feature of Peirce's objective idealism: namely, if "all our knowledge is, and forever must be, relative to human experience and to the nature of the human mind" (CP 6.95 [1903]), it remains that "all experience and all knowledge is knowledge of that which is, independently of being represented." 11

Remind indeed that Peirce's defense of a triune reality lies in this fact "which all ordinary people will see plainly enough; that the essence of the realist's opinion is that it is one thing to be and another thing to be represented" (CP 8.129 [1902]). This, as we have seen, explains why Peirce was for instance "confident that the bull and I feel much alike at the sight of a red rag" (EP2: 192 [1903]); that if "a man [walks] down Wall Street debating within himself the existence of an external world [and] jostles up against somebody who angrily draws off and knocks him down, the sceptic is unlikely to carry his skepticism so far as to doubt whether anything beside the ego was concerned" (CP 1.431 [ca. 1896]); and that if "we admit that the law has a real being, [...] then the future necessary consequent of a present state of things is as real and true as that present state of things itself" (CP 6.368 [1902]).

Hence, whether it be an unrepresented and unembodied possible quality, an unrepresented and reacting actual existent, or a necessarily represented law according to which a future state of things may be predicted, all three kinds of elements may be deemed as real. 


\section{Representing the Real World}

Now, as planned, let us see how the three kinds of elements must be recognized at once in true propositions, taking one of Peirce's canonical examples as an illustration: the hardness of a diamond.

\section{1. "This Diamond is Hard"}

If one wishes to represent that a particular diamond really is hard, for instance, one has indeed to recognize the reality of all three kinds of elements. In the first place, one has to admit the reality of hardness, as a possible quality being such as it is whether it be embodied or not and represented or not. Hardness is a first and its mode of being is a mere positive qualitative possibility (distinguishable from, say, softness). In the second place, one has to admit the reality of the (supposedly hard) diamond, an insistent existent thing brutely acting upon other things and upon my senses in such wise that it is actually capable of determining the very representation that is to be made of it, whether that representation, at this stage, be true or not. This (supposedly hard) diamond is a second and its mode of being is a reactive actuality. Finally, in the third place, one has to admit the reality of the law according to which something hard would behave if it really were hard. A law is a third and its mode of being is that of a general necessity.

Now, that which is purposed to represent an object as it really is, that is, as being such as it is, independently of its being represented, is a general propositional sign. It happens indeed that such a general sign, once instantiated in context, may be interpreted as representing (a) the existent object to which the proposition is actually related (e.g. a diamond), (b) the possible character which is supposedly possessed by its object (e.g. hardness), and (c) the actual relation which is said to really subsist between the object and the professed character. As it turns out, the object is indicated by a proposition's subject-part, the possible character is signified by its predicate-part, and the actual relation between the two is expressed by the very "co-localization" of the two parts (Stjernfelt, 2014, 2015). A general proposition, once instantiated in context, is thus purposed to signify a fact about an object: for instance, the actual fact that hardness is embodied by this singular diamond, to which the proposition is itself related, and to which it applies.

More technically, propositions are meant to be asserted in context. A proposition does indeed profess to be virtually true, but a same proposition can actually be used in both fictive and veridictive discourse. Therefore, there has got to be "something more" differentiating the two kinds of usage. Peirce identified it as an act of assertion: "an act of assertion supposes that, a proposition being formulated, a person performs an act which renders him liable to the penalties of the social law (or, at any rate, those of the moral law) in case it should not be true, unless he has a definite and sufficient excuse" ${ }^{12}$ (EP2: 278 [1903]). Only such a conventional act may distinguish between a proposition which renders its enunciator "responsible for its truth" (CP 5.543 [ca. 1902]) and one that does not. ${ }^{13}$ However, in so far as "that which any true proposition asserts ${ }^{14}$ is real, in the sense of being as it is regardless of what you or I may think [i.e. represent] about it" (EP2: 343 [1905]), it remains to be seen how we can be so sure that a general proposition really conforms to the singular fact which it is purposed to represent? In 
other words, in so far as "truth is the correspondence of a representation with its object" (EP2: 379 [1906]), how can we be so sure that a general proposition, once instantiated and asserted in context, is true of its object? ${ }^{15}$

\subsection{The Truthfulness of Propositions}

30 The answer, said Peirce, lies in the "application of the sole principle of logic which was recommended by Jesus; 'Ye may know them by their fruits"' (CP 5.402n2 [1878]). It lies in the future. Here is Peirce's argument, which I develop following up on the previous example. The peculiar instantiated proposition, by means of which an enunciator asserts that a given diamond is hard, may only be conceived to truly conform to the (supposedly real) fact that it embodies hardness if and only if that diamond would act like the hard thing it is represented to be: for instance, if the diamond really is hard, then it would resist an attempt to leave a mark, if scratched: "Take any general term whatever. I say of a stone that it is hard. That means that so long as the stone remains hard, every essay to scratch it by the moderate pressure of a knife will surely fail. To call the stone hard is to predict that no matter how often you try the experiment, it will fail every time. That innumerable series of conditional predictions is involved in the meaning of this lowly adjective" (EP2: 254 [1903]). Accordingly, the truth of a proposition necessarily hinges upon the future actualization of the conditional predictions implied by its predicate, as they may be stated by means of an argument. This amounts to saying that the truth of a proposition hinges upon the real government of the possible laws by means of which its object is presumably determined and affected. Corollarily, the falsity of a proposition hinges upon the possible discrepancies between expected results (as theoretically predicted by a law) and the ones ultimately taking place in actual fact, by means of experimentation. Errors and doubt may thus be forced upon us, whether we like it or not.

31 This overall argumentation, of course, expresses Peirce's pragmaticist doctrine, as it was clearly defined in 1907: "that the total meaning of the predication of an intellectual concept consists in affirming that, under all conceivable circumstances of a given kind, the subject of the predication would (or would not) behave in a certain way, - that is, that it either would, or would not, be true that under given experiential circumstances [...] certain facts would exist, - that proposition I take to be the kernel of pragmatism. ${ }^{16}$ More simply stated, the whole meaning of an intellectual predicate is that certain kinds of events would happen [...] under certain kinds of existential circumstances" (EP2: 401 [1907]). In short, Peirce's position thus forces us to recognize that the only way to admit that general propositions may ever be conceived to be true of particular objects which we certainly do all the time - is to recognize that those objects may possibly be governed by real laws. ${ }^{17}$ All in all, therefore, truthfulness requires a recognition of all three real elements: real qualities, real existents, and real laws.

\subsection{The Role of Inquiry}

Naturally, in the course of life, we do not test the truthfulness of asserted propositions by means of controlled experiments (although we might always do it in principle): we rely instead on the good faith of their enunciators and act instead upon beliefs, understood following Scottish philosopher Alexander Bain's definition as "that upon which a man is prepared to act" (EP2: 399 [1907]): "to assert a predicate of certain 
subjects [...] means, - intends, - only to create a belief that the real things denoted by those subjects possess the real character or relation signified by the predicate"18 (EP2: 427 [1907]).

However, the testing of the truthfulness of propositions, by means of experimentation, does happen to be the norm of scientific inquiries. According to Peirce, the scientific method (next to that of tenacity, authority, and a priori) is indeed the most successful one for settling opinion, or "fixing belief," which is an incessant hope animating the scientific community. More precisely, a scientist's business is to test the reality of hypothesized laws, or general principles, whose possible government could explain a peculiar kind of phenomena. Hence, the possibility of real governing laws becomes an indispensable postulate of scientific inquiry as well, just as a faith in the intelligibility of the world is an ethical imperative for scientists. Once possible laws are guessed, they may be subsequently tested by means of experiments and, if confirmed, constitute the basis for predictions. If they are not confirmed, however, new batteries of hypotheses will have to be submitted, and opinions will have to be revised ${ }^{19}$ ).

It follows that, in general, a scientific truth constitutes a belief to which a sufficiently carried inquiry is ultimately predestined to lead, and that the real becomes precisely that which a final belief shall ultimately represent. And because scientists necessarily err in their particular inquiries, the real is indeed that which "has such characters as it has independently of what any particular mind or minds may think those characters may be" (EP2: 532 [1903]; our emphasis): one thought, or even more, may be wrong, but countless thoughts that are carried sufficiently far are logically destined to be right. Peirce thus argued that "the different sciences deal with different kinds of truth; mathematical truth is one thing, ethical truth is another, the actually existing state of the universe is a third; but all these different conceptions have in common something very marked and clear. We all hope that the different scientific inquiries in which we are severally engaged are going ultimately to lead to some definitely established conclusion, which conclusion we endeavor to anticipate in some measure. Agreement with that ultimate proposition that we look forward to, - agreement with that, what it turns out to be, is the scientific truth" (EP2: 87 [1901]).

\section{Conclusion}

Somewhere else, having conducted a lexicometric analysis of Peirce's Collected Papers, I showed that the two most cited (substantive) terms in those writings were precisely truth and proposition (Gaspard 2019). In light of the present essay, this result is not surprising: Peirce's philosophical interests, an outgrowth of his own background as a research scientist, do seem focused on the "logicality" of things. Peirce was thus among the first systematic thinkers to have connected traditional questions of metaphysics (see, for instance, his focus on a list of post-kantian categories, his re-reading of scholastic realism, his nuanced take on idealism, etc.) with an emerging "philosophy of science," focusing on the logic of scientific inquiry, and an equally pioneering "philosophy of logic," concentrating on relatives and the classification of arguments (see, for instance, Hookway (1985) for an overview of Peirce's architectonics). Furthermore, his constant appraisal of the nature of reasoning and of representations in particular, construed as ingredients of thought, has been central to this effort. His pragmaticism, of which I strived to offer a "synoptic" (hence necessarily partial) 
overview in this article, is then purported to connect these views into one unified system.

Peirce's reflections, among other things, evolved into an impressive but fragmented doctrine of signs, that needs to be read in light of this unified and systematic approach. At the turn of the century, Peirce actually reached the point where he equated Logic with Semeiotic, understood as "the quasi-necessary, or formal, doctrine of signs" in general (CP 2.227 [ca. 1897]). More specifically, he added that "by describing the doctrine as 'quasi-necessary,' or formal, I mean that we observe the characters of such signs as we know, and from such an observation, [...] we are led to statements [...] as to what must be the characters of all signs used by a 'scientific' intelligence, that is to say, by an intelligence capable of learning by experience" (ibid.). As he came to conceive it, "Logic, considered as Semeiotic" (SS 80 [1908]) was to comprise three branches: pure grammar, logic proper, and pure rhetoric. The task of pure grammar is to ascertain "what must be true of the [signs] used by every scientific intelligence in order that they may embody any meaning" (CP 2.229 [ca. 1897]). The task of logic proper (or critical logic) is to ascertain "what is quasi-necessarily true of the [signs] of any scientific intelligence in order that they may hold good of any object, that is, may be true" (ibid.). Finally, the task of pure rhetoric is to ascertain "the laws by which in every scientific intelligence one sign gives birth to another, and especially one thought brings forth another" (ibid.).

Peirce's famous trichotomies of signs thus aims at defining the possible kinds of ways by means of which such a "scientific intelligence" may get to know or represent the real. For instance, as we have seen, terms (subjects and predicates), propositions, and arguments are the three kinds of symbols, or generals signs, fit to signify, or be interpreted as signifying, possible characters (as predicates), possible objects (as subjects - with the help of indexical signs), possible facts about objects (as propositions connecting subjects and predicates), and possible rational connections between facts about objects (as arguments connecting premises leading to conclusions). In light of this overview, Peirce's contention that "the value of a symbol is that it serves to make thought and conduct rational and enables us to predict the future" (CP 4.448 [ca. 1903]) takes on its full meaning. Following an old trend in Peircean studies, I thus hope this paper succeeded in showing that no parts of his philosophy shall be studied in themselves, amputated from the systematic whole to which they belong.

\section{BIBLIOGRAPHY}

BELLUCCI Francesco, (2018), Peirce's Speculative Grammar: Logic as Semiotics, New York and London, Routledge.

BERgMAn Mats, (2009a), “Experience, Purpose, and the Value of Vagueness: On C. S. Peirce's Contribution to the Philosophy of Communication," Communication Theory, 19 (3), 248-77.

BERGMAN Mats, (2009b), Peirce's Philosophy of Communication. The Rhetorical Underpinnings of the Theory of Signs, London, Continuum International Publishing Group. 
BOLER John F., (1963), Charles Peirce and Scholastic Realism: A Study of Peirce's Relation to John Duns Scotus, Seattle, University of Washington Press.

BOYD Kenneth \& Diana HENEY, (2017), "Rascals, Triflers, and Pragmatists: Developing a Peircean Account of Assertion," British Journal for the History of Philosophy, 25 (2), 287-308.

DE TIENNE André, (1996), L'analytique de la représentation chez Peirce: la genèse de la théorie des catégories, Bruxelles, Facultés universitaires Saint-Louis.

ENGEL-TIERCELIN Claudine, (1992), "Vagueness and the Unity of C. S. Peirce's Realism," Transactions of the Charles S. Peirce Society, 28 (1), 51-82.

FISCH Max. H., (1986), Peirce, Semeiotic, and Pragmatism. Essays by Max H. Fisch, edited by Kenneth Laine Ketner \& Christian Kloesel, Bloomington, Indiana University Press.

FREADMAN Anne, (2004), The Machinery of Talk. Charles Peirce and the Sign Hypothesis, Stanford, Stanford University Press.

GASPARD Jeoffrey, (2019), “'My Inordinate Reluctance to Repeat a Word.' A Lexicometric Report on Peirce's Collected Papers," Transactions of the Charles S. Peirce Society, 55 (1), 39-48.

HоoKway Christopher, (1985), Peirce, London, Routledge \& Kegan Paul.

LANE Robert, (2018), Peirce on Realism and Idealism, Cambridge, Cambridge University Press.

MURPHEY Murray G., (1961), The Development of Peirce's Philosophy, Cambridge, MA, Harvard University Press.

PEIRCE Charles Sanders, (1931-1935), Collected Papers of Charles Sanders Peirce. Vols. 1-6, edited by Charles Hartshorne \& Paul Weiss. 1958, vols. 7-8, edited by Arthur Burks, Cambridge, MA, Harvard University Press. References are to $\mathrm{CP}$, in decimal notation, by volume and paragraph number.

PEIRCE Charles Sanders, (1977), Semiotic and Significs. The Correspondence between Charles S. Peirce and Victoria Lady Welby, edited by C. S. Hardwick, Bloomington, Indiana University Press. References are to SS.

PEIRCE Charles Sanders, (1982-2009), Writings of Charles Sanders Peirce: A Chronological Edition, vols. 1-8, edited by the Peirce Edition Project, Bloomington and Indianapolis, Indiana University Press. References are to $\mathrm{W}$ followed by volume and page number.

PEIRCE Charles Sanders, (1998), The Essential Peirce: Selected Philosophical Writings, volume 2 (1893-1913), edited by the Peirce Edition Project, Bloomington and Indianapolis, Indiana University Press. References are to EP followed by volume and page number.

RÉTHORÉ Joëlle, (1993), “A Few Linguistic Concepts Revisited in the Light of Peirce’s Semiotics," Semiotica, 97 (3/4), 387-400.

ROBIN Richard S., (1967), Annotated Catalogue of the Papers of Charles S. Peirce, Amherst, University of Massachusetts Press. References are to R followed by manuscript and page number.

RODRIGUES Cassiano T., (2011), “The Method of Scientific Discovery in Peirce's Philosophy: Deduction, Induction, and Abduction," Logica Universalis, 5 (1), 127-64.

SHORT Thomas L., (2007), Peirce's Theory of Signs, Cambridge, Cambridge University Press.

STJERNFELT Frederik, (2014), Natural Propositions. The Actuality of Peirce's Doctrine of Dicisigns, Boston, Docent Press. 
STJERNFElT Frederik, (2015), “Dicisigns: Peirce's Semiotic Doctrine of Propositions," Synthese, 192 (4), 1019-54.

WIGGINs David, (2004.), "Reflections on Inquiry and Truth Arising from Peirce's Method for the Fixation of Belief," in Cheryl Misak (ed.), The Cambridge Companion to Peirce, Cambridge, Cambridge University Press, 87-126.

\section{NOTES}

1. As a matter of fact, in an 1892 paper on the critic of arguments published by The Open Court, Peirce granted that his logical enquiries stood in line with those of Kant and Hegel, in sharing a similar affinity for triads: "Kant taught that our fundamental conceptions are merely the ineluctable ideas of a system of logical forms; nor is any occult transcendentalism requisite to show that this is so, and must be so. [...] That there are three elementary forms of categories is the conclusion of Kant, to which Hegel subscribes; and Kant seeks to establish this from the analysis of formal logic. Unfortunately, his study of that subject was so excessively superficial that his argument is destitute of the slightest value. Nevertheless, his conclusion is correct; for the three elements permeate not only the truths of logic, but even to a great extent the very errors of the profounder logicians" (CP 3.422 [1892]). In his second 1898 Cambridge lecture, he stated in the same vein: "Why should there be three principles of reasoning, and what have they to do with one another? This question, which was connected with other parts of my schedule of philosophical inquiry that need not be detailed, now came to the front. Even without Kant's categories, the recurrence of triads in logic was quite marked, and must be the croppings out of some fundamental conceptions. I now undertook to ascertain what the conceptions were. This search resulted in what I call my categories" (CP 4.3 [1898]).

2. Peirce's conception of the real would broadly remain unchanged throughout his writings. For instance, in his early review of Fraser's The Works of George Berkeley, from 1871, he had already argued that "objects [of representations] are divided into figments, dreams, etc., on the one hand, and realities on the other. The former are those which exist only inasmuch as you or I or some man imagines them; the latter are those which have an existence independent of your mind or mine or that of any number of persons" (W2: 467 [1871]). A few years later, in the well-known How to Make Our Ideas Clear, published in 1878, he suggested that "we may define the real as that whose characters are independent of what anybody may think them to be" (W3: 271 [1878]). In the same vein, in his later years, he came to declare that "we must mean by the real that which has such characters as it has independently of what any particular mind or minds may think those characters may be" (EP2: 532 [1903]), and that "to say that a thing is Real is merely to say that such predicates as are true of it, or some of them, are true regardless of whatever any actual person or persons might think concerning that truth" (EP2: 456 [1909]). In other words, the real is that which "is unaffected by what we may think of it" (W2: 467 [1871]). Really being is thus ontologically different from being represented (see, for instance, EP2: 303 [1904] on that matter).

3. Peirce actually took no prisoners as far as nominalism was concerned. For instance, in one draft of his 1907 rejected letter on pragmatism to the editors of The Nation and The Atlantic Monthly, he lamented that "the nominalistic color which an apparent accident made ascendant even to this day throughout European philosophy is merely that perversion of pragmatism which consists in denying any other mode of real being than existence" ( $R$ 320:18 [ca. 1907]). This led him to conclude that "all modern philosophy of every sect has been nominalistic" (CP 1.19 [1903]).

4. Thus, because a quality is not "dependent, in its being, upon the fact that some material thing possesses it" (CP 1.422 [ca. 1896]), "the error of [the nominalists] lies in holding that the 
potential, or possible, is nothing but what the actual makes it to be" (ibid.). Similarly, another error would consist in rightfully recognizing that "all colors are relative to the sense of sight" but failing to notice that "there is a difference between a color and a sensation of color. For a color is a quality of a thing which remains the same whether it be exposed to one kind of illumination or to another, and whether it be seen by a normal or by a color-blind. Such is the established signification of the word "color"' (CP 6.327 [1909]). As a matter of fact, two things could not be thought of as alike were it not for some real quality which would happen to be possessed by the two things compared.

5. In an unidentified fragment, Peirce thus reminded that the word actual "is due to Aristotle's

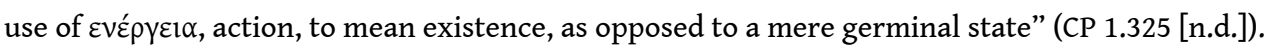

6. According to Peirce, a "prescission," being one of the three grades of mental separation with discrimination and dissociation, "consists in supposing a state of things in which one element is present without the other, the one being logically possible without the other" (EP2: 270 [1903]). In other words, that which is "prescinded" is that which cannot be dissociated from something else but which may still be supposed, or conceived, to be separate from that something else. In other words, that which is prescinded is that which may be focused on, to the neglect of something else (cf. W2: 50 [1867]).

7. Taking an inkstand as an example, Peirce described its existence in the following terms: "If I turn away my eyes, other witnesses will tell me that it still remains. If we all leave the room and dismiss the matter from our thoughts, still a photographic camera would show the inkstand still there, with the same roundness, polish and transparency, and with the same opaque liquid within. Thus, or otherwise, I confirm myself in the opinion that its characters are what they are, and persist at every opportunity in revealing themselves, regardless of what you, or I, or any man, or generation of men, may think that they are. That conclusion to which I find myself driven, struggle against it as I may, I briefly express by saying that the inkstand is a real [existent] thing" (EP2: 62 [1901]). In a draft review of Karl Pearson's Grammar of Science, Peirce suggested along the way that "there is a blind force about the inkstand by which it crowds its way into our universe in spite of all we can do" (CP 8.153 [ca. 1900]).

8. Regarding predictions, Peirce argued in one of his 1903 Lowell Lectures that "five minutes of our waking life will hardly pass without our making some kind of prediction; and in the majority of cases these predictions are fulfilled in the event. [...] To say that a prediction has a decided tendency to be fulfilled, is to say that the future events are in a measure really governed by a law. [...] If the prediction has a tendency to be fulfilled, it must be that future events have a tendency to conform to a general rule" (CP 1.26 [1903]). In defining uniformity for the Baldwin's Dictionary, Peirce explained the problem in these other terms: "If I have tried the experiment with a million stones and have found that every one of them fell when allowed to drop, it may be very natural for me to believe that almost any stone will act in the same way. But if it can be proved that there is no real connection between the behaviour of different stones, then there is nothing for it but to say that it was a chance coincidence that those million stones all behaved in the same way; for if there was any reason for it, and they really dropped, there was a real reason, that is, a real general [law]. Now if it is mere chance that they all dropped, that affords no more reason for supposing that the next will drop than my throwing three double sixes successively with a pair of dice is a reason for thinking that the next throw will be double sixes" (CP 6.99 [1902]). Accordingly, the possibility of conditional prediction is what differentiates the coincidental regularity of a chance succession from the regularity of a real, governing law.

9. It is indeed equivalent to say that "all stones fall" and to say that "if $x$ is a stone and $x$ is dropped, then $x$ would fall."

10. Here again, then, a choice between nominalism and realism had to be done in so far as a "law [may be] distinguished from brute fact, either, as the nominalists say, by being a product of the human mind [i.e. a representation], or, as the realists say, by being a real intellectual ingredient 
of the universe" (EP2: 425 [1907]). Of course, the second alternative was the one decidedly chosen by Peirce: "My argument to show that law is reality and not figment - is nature independently of any connivance of ours - is that predictions are verified" (CP 8.153 [ca. 1900]). Over time, there remained for him to conclude that "after physical science has discovered so many general principles in Nature, nominalism becomes a disgraceful habitude of thought" (CP 6.175 [1906]).

11. When absolute idealists would conclude that metaphysical conceptions, because they "repose upon their being involved in the forms of logic, are only valid for experience and since all our knowledge is relative to human mind, [...] are not valid for things as they objectively are" (CP 6.95 [1903]). As a matter of fact, however, "even lies invariably contain this much truth, that they represent themselves to be referring to something whose mode of being is independent of its being represented." On this important balance in Peirce's thought between realism and idealism, see the recently published book by Lane (2018).

12. That an act of assertion renders its enunciator "liable to the penalties of the social law" is rendered explicit in the taking of an oath: "If a man desires to assert anything very solemnly, he takes such steps as will enable him to go before a magistrate or notary and take a binding oath to it. Taking an oath is not mainly an event of the nature of a setting forth, Vorstellung, or representing. It is not mere saying, but is doing. The law, I believe, calls it an 'act.' At any rate, it would be followed by very real effects, in case the substance of what is asserted should be proved untrue. This ingredient, the assuming of responsibility, which is so prominent in solemn assertion, must be present in every genuine assertion. For clearly, every assertion involves an effort to make the intended interpreter believe what is asserted, to which end a reason for believing it must be furnished" (CP 5.546 [ca. 1908]).

13. As it is here evidenced, Peirce was thus a major precursor of modern pragmatics, a historical fact now widely recognized (see, for instance, Réthoré 1993; Bergman 2009a \& 2009b; Boyd \& Heney 2017; and Bellucci 2018). Regarding fiction in particular, Peirce posited that "the real world cannot be distinguished from a fictitious world by any description. It has often been disputed whether Hamlet was mad or not. This exemplifies the necessity of indicating that the real world is meant, if it be meant. [...] It is true that no language (so far as I know) has any particular form of speech to show that the real world is spoken of. But that is not necessary, since tones and looks are sufficient to show when the speaker is in earnest. These tones and looks act dynamically upon the listener, and cause him to attend to realities" (CP 2.337 [ca. 1895]).

14. Here, Peirce misuses language, for it is not the proposition in itself which asserts something but the proposition as it is used in an act of assertion.

15. Note that propositions are the only kind of (general) signs which may possibly be true or false of their object, while their predicates and subjects, by themselves, may be neither. Indeed, predicates, if they do signify possible characters, do not indicate the actual existents to which they may belong, and subjects, if they do indicate existents, do not explicitly signify their character. Accordingly, no subject or predicate can ever be used to assert anything by themselves, while a proposition can.

16. Peirce actually coined the term pragmaticism to differentiate his own kind of pragmatism from other kinds which he did not entirely condone. Nevertheless, Peirce still used the term pragmatism in numerous places.

17. Note that the truth of propositions may also hinge upon socially established laws. For instance, someone may be truly represented as "king" in so far as "certain conditional rules shall govern the conduct" of the "king" and its subjects accordingly. But if the king's subjects (e.g. civil society, the military, etc.) fall short of implementing those conditional rules, the king then becomes instantly stripped of his clothes. This explains why social realities may collapse at once: real social laws are indeed less crystallized than real natural laws, the former losing their governing power more easily than the latter. 
18. Note that a symbolic predicate may represent any kind of character, not only qualities. Peirce distinguishes indeed between monadic (e.g. "is blue"), dyadic (e.g. "kills"), and polyadic characters (e.g. "gives to"). That characters may concern more than one subject does not contradict the logic of what is stated above. However, Peirce insisted that polyadic characters could not be conceived as belonging to a subject independently of its being represented as belonging to that subject by means of a general predicate. For instance, John does not give a gift to Paul independently of John being represented as doing so. This is because "giving" is not immediately observable like "killing" is. Indeed, an act of giving consists in the instantiation of a necessarily represented law (i.e. the socially instituted "law of giving"), and whose real government may only be verified if conditional predictions based on it are actually borne out by future events. Said Peirce: "If $A$ gives $B$ to $C$, he, $A$, acts upon $B$, and acts upon $C$; and $B$ acts upon $C$. Perhaps, for example, he lays down $B$, whereupon $C$ takes $B$ up, and is benefited by $A$. But these three acts might take place without that essentially intellectual operation of transferring the legal right of possession, which axiomatically cannot be brought about by any pure dyadic relationships whatsoever" (CP 6.323 [1909]). It follows that "the mere transfer of an object which $A$ sets down and $C$ takes up does not constitute giving. There must be a transfer of ownership and ownership is a matter of Law" (EP2: 171 [1903]) - it implies that "certain conditional rules shall govern the conduct of $A$ and of $C$ " (CP 1.475 [1896]). On the other hand, that an actual existent embodies a quality or that two existents react against each other do not have to be represented as such in order to be phenomenologically apprehended: those monadic and dyadic characters are immediately given in perception (i.e. through feelings and senses of reaction, respectively) and, as such, are constitutive of their respective kind of dyadic (perceptual) fact. This brings a division of facts distinguishing between monadic, dyadic, and polyadic facts, the latter being necessarily "intellectual" or "mental," that is, dependent on thought and representation.

19. For a more thorough account of Peirce's logic of scientific inquiry, see Wiggins (2004) and Rodrigues (2011).

\section{ABSTRACTS}

This essay attempts an overview of Peirce's pragmaticist doctrine of the truth of propositions. Relying on his writings, I try to characterize his conception of the real and discuss the ways in which his peculiar scholastic metaphysics, opposing that of nominalists, is a central tenet of the pragmaticist view of truth which he strived to develop. Peirce conceived indeed real possibilities and real necessities to be just as real as actualities, those realities corresponding in nature to qualities ("firsts"), laws ("thirds"), and existents ("seconds"), respectively. More specifically, I detail the peculiar mode of being of each kind of real elements and show that all three categories must be recognized at once in true propositions. This led Peirce to conclude that if propositions are general signs indeed and, as such, along with terms and arguments, are necessarily dependent on mind, it does not in the least preclude those propositions to be about, nor true of, a real world - a position which actually constitutes a necessary prerequisite for any meaningful conception of scientific inquiry. I believe that a focus on such interrelations between Peirce's categorial account of the real and Peirce's pragmaticist conception of truth constitutes an ideal testament to the systematic nature of his thought, which is an aspect often deflated in unspecialized literatures. 
AUTHOR

JEOFFREY GASPARD

Université libre de Bruxelles

jeoffrey.gaspard[at]ulb.be 